\title{
HOW DO AUSTRALIAN SMALL AND MEDIUM ENTERPRISES COMMUNICATE THEIR ENVIRONMENTAL IMPROVEMENT ACTIVITIES ONLINE?
}

\author{
Craig M. Parker
}

School of Information Systems

Deakin University, Australia

craig.parker@deakin.edu.au

\section{Bardo Fraunholz}

School of Information Systems

Deakin University, Australia

bardo.fraunholz@deakin.edu.au

\section{Ambika Zutshi}

School of Management \& Marketing

Deakin University, Australia

ambika.zutshi@deakin.edu.au

\section{Merete Crofts}

School of Information Systems Deakin University, Australia merete.crofts@deakin.edu.au

\begin{abstract}
There have been calls in the IS/eBusiness literature for research on "green" IS/IT in a Small and Medium Enterprises (SMEs) context. The Corporate Social Responsibility (CSR) literature has neglected the issue of how SMEs can use websites to communicate their environmental improvement activities. This paper links these two previously separate disciplines by reporting on a content analysis of 443 Australian SME websites from four industry sectors to identify if and how they use websites to communicate their environmental improvement activities. The study found that 47 websites were communicating such activities in some form. A detailed analysis was undertaken of these 47 websites to identify emergent themes relating to how these SMEs were communicating their environmental improvement activities. These themes resulted in a reconceptualisation of the traditional "4 Ps" of marketing for online communication of environmental improvement activities by SMEs: profile; product; process; and prominence.
\end{abstract}

\section{INTRODUCTION}

Environmental improvement has received increased attention by practitioners and academics for at least the last two decades. For the purposes of this paper we define environmental improvement as 
changes in technology and practices which reduce an organisation's current level of negative environmental impact (Parker et al., 2009). The rationale for businesses to engage in environmental improvement is often promoted on economic grounds such as giving businesses a marketing edge (Gadenne et al., 2008; Nielsen \& Thomsen, 2009) and saving costs from reducing the use of resources (Bradford \& Fraser, 2008; Revell \& Blackburn, 2007).

Most of the research has focused upon the environmental improvement activities of large organisations (Blomback \& Wigren, 2009; Jenkins, 2006; Spence, 2007). Environmental improvement research on small and medium enterprises (SMEs) in an IS/eBusiness context is currently lacking and is important for four reasons:

1. The relevance of environmental improvement was highlighted recently by Elliot (2009) who calls for research into IS-related environmental sustainability issues, especially in the context of SMEs. The limited but growing literature on what has been termed green IS (or IT) currently focuses on issues such as: the carbon emissions from IT infrastructure (Vykoukal et al., 2009); the energy efficiency of software (Capra \& Merlo, 2009); the environmental criteria for IS/IT procurement (Molla, 2009) and evaluation (Piotrowicz \& Cuthbertson, 2009); and the IS/IT product lifecycle which results in e-waste and illustrates the need for recycling (Elliott, 2007). Research to date has not considered IT or IS related environmental improvement issues from an SME perspective.

2. SMEs are not the same as large firms because they often have fewer resources, flat organisational structures, focus on "survival" (MacGregor \& Vrazalic, 2005; Parker et al., 2009) and are less likely to sign up to environmental improvement agreements or standards (Spence, 2007). This means that environmental improvement (as well as IS/eBusiness) research on large firms does not always provide insights into the improvement activities of or benefits for SMEs.

3. SMEs account for the majority of firms in many world economies (Parker et al., 2009). For example, SMEs comprise 99\% of all Australian firms, which are those with less than 200 employees (ABS, 2007).

4. There are no Australian figures to quantify the environmental impact of SMEs, the UK Government estimates that UK SMEs collectively generate $60 \%$ of all commercial carbon emissions (Marshall Report, 1998) and produce $60 \%$ of all commercial waste (Environmental Agency, 2002). These statistics are unsubstantiated and now quite dated. Nonetheless, even today UK researchers and policy makers use these statistics to justify the importance of research into and policy action relating to SMEs and environmental improvement. For this reason, we could safely assume that in other developed economies, such as Australia, large numbers of SMEs would have a significant negative impact, collectively, on the environment.

The limited literature which has examined SMEs and environmental improvement has tended to focus on examining barriers/drivers and on identifying what environmental improvement activities SMEs promote (Parker et al., 2009) rather than exploring how they promote their activities to stakeholders. This paper addresses this gap by reporting on how Australian SMEs use their websites to communicate their environmental improvement activities. This exploratory, qualitative study involved a content analysis of 443 Australian SME websites, with a focus on 47 websites in which there was some communication about environmental improvement activities. We decided to focus on website communication because recent survey results suggest that $57 \%$ of small businesses and $87 \%$ of medium businesses in Australia have websites (Sensis, 2009). For this reason, we anticipated that there was sufficient website adoption amongst Australian SMEs to examine how this channel was used for communicating environmental improvement activities. We see websites as an important way in which SMEs can communicate these activities because Australian SMEs are increasingly using websites as a marketing tool (Sensis, 2009). 
This paper makes four important contributions to knowledge:

1. There is very little Australian research published on SME environmental improvement, with most literature reporting on European and North American studies. We found only ten Australian studies (Altham, 2007; Condon, 2004; Gadenne et al., 2008; Gunningham \& Sinclair, 2002; Howgrave-Graham \& van Berkel, 2007; Kerr, 2006; McKeiver \& Gadenne, 2005; Redmond et al., 2008; Schaper, 2002; Walker et al., 2008) out of around 150 journal articles published in this area. This study therefore makes an important contribution to this limited Australian literature and associated knowledge.

2. This paper is the first stage of a larger longitudinal research project which aims to examine whether regulations such as Australia's planned carbon trading scheme means that, over time, Australian SMEs will increase their environmental improvement communication. In this context, the paper makes an important contribution to knowledge by providing a baseline of the current state of SME online communication of environmental improvement which can be used as the basis for longitudinal research.

3. The findings of this study suggest that the traditional principles of marketing (based on product, promotion, price and place) are not appropriate for explaining how SMEs can communicate their environmental improvement activities online. This paper makes an important conceptual contribution by presenting an alternative conceptualisation of online marketing, in the context of environmental improvement, based on profile, product, process and prominence.

4. The paper suggests a number of directions for future research which, if followed by the IS/eBusiness research community, will result in further contributions to knowledge. This future research will generate new insights into how SMEs globally communicate their environmental improvement activities online (as well as via other channels).

Furthermore, this paper offers a practical contribution by providing insights into how SMEs (in Australia and overseas) can use websites to promote their environmental improvement activities.

The paper is structured as follows. In the next section we provide a review of the existing literature concerning SMEs and environmental improvement, with a particular focus on the way in which they promote their activities in this area. We then justify our research approach which involved undertaking content analyses of Australian SME websites. We then present our findings under various emergent themes relating to how Australian SMEs communicate their environmental improvement activities online. We then discuss the implications of the findings for theory, practice and future research opportunities. The paper ends with concluding remarks.

\section{LITERATURE REVIEW}

\section{Environmental Improvement and Large Organisations}

There is an extensive body of literature on environmental improvements made primarily by large organisations in the past few decades (Blomback \& Wigren, 2009; Jenkins, 2006; Spence, 2007). One area of research focus has been to examine the environmental reports of these large organisations, which typically take the form of Corporate Social Responsibility (CSR) reports and/or are embedded in corporate annual reports (e.g. Haddock-Fraser \& Fraser, 2008; Martin \& Hadley, 2008; Pollach et al., 2009; Spence, 2009). There are various motivations for why large organisations might report on their environmental improvement activities and these can be broadly categorised into three groups:

1. Large organisations in some countries are subject to environmental regulations and are required to report to government stakeholders (Martin \& Hadley, 2008). These regulations can specify 
guidelines and standards for reporting on greenhouse gas emissions, energy consumption and energy production. For example, in Australia many large organisations (e.g. electricity producers and upstream fuel suppliers) are required to report on their carbon emissions under the National Greenhouse and Energy Reporting Act 2007 (Australian Government, 2010).

2. Shareholders and investors as organisational stakeholders can also motivate large organisations to report on environmental improvement activities (Haddock-Fraser \& Fraser, 2008; Martin \& Hadley, 2008; Spence, 2009). These reports can be used by shareholders and investors to make informed decisions on whether or not to be associated with an organisation.

3. The third group of stakeholders to which large organisations can report include customers and the public more generally. Some authors have found that large organisations exposed to the public or consumers directly (or those with a recognised brand name) were more likely to report compared to those which sell to other businesses (e.g. Haddock-Fraser \& Fraser, 2008). A common motivation is the positive publicity which environmental improvement reporting can generate because it promotes a positive image of the firm in the eyes of customers and the public (Martin \& Hadley, 2008; Pollach et al., 2009; Spence, 2009; Tate et al., 2009). There can also be a cultural dimension, as evident in Maali et al.'s (2006) study which found that Islamic banks present a "social face" so the Muslim public feels confident that bank transactions are free of interest and speculation and that the bank embraces the brotherhood between Muslims.

There has been comparatively less research carried out on SMEs and their environmental improvement reporting. In the next section we provide an overview of the nature of SME related research on environmental improvement and the issues influencing their reporting activities.

\section{Environmental Improvement and SMEs}

The limited research on SMEs and environmental improvement has mainly focused on examining the barriers, drivers and benefits for SMEs and on describing the environmental improvement activities which are undertaken by SMEs (Jenkins, 2006; Parker et al., 2009). These activities include conserving energy and water, reducing waste and pollution, and offering eco-friendly products and services to customers (Parker et al., 2009). The factors affecting the extent of environmental improvement by SMEs, and their reporting/communication of these activities to stakeholders, are now reviewed.

Unlike large organisations, SMEs are generally not required to report to governments (at least in Australia) about their environmental improvement activities (Parker et al., 2009). This is because many governments avoid targeting SMEs with regulation because it is anticipated that regulations would burden SMEs unnecessarily (Clement \& Hansen, 2003; Drake et al., 2004; Revell \& Blackburn, 2007; Simpson et al., 2004). Interestingly, however, regulations have been found to be ranked highly by many SME owner-managers as a driver of environmental improvement (Bradford \& Fraser, 2008; Pimenova \& van der Vorst, 2004; Revell \& Blackburn, 2007; Studer et al., 2006; Williamson et al., 2006).

Environmental improvement by SMEs is often driven by an owner-manager's sense of moral duty, personal values and environmental commitment (Gueben \& Skerratt, 2007), as well as by employees (Jenkins, 2006; Lawrence et al., 2006). However, this does not necessarily mean that owner-managers will report or communicate externally their environmental improvement activities. For example, some researchers have found that owner-managers tend to engage in environmental improvement for their own sake, feel uncomfortable about promoting these activities, and believe environmental improvement communication is more about marketing propaganda which is typical of large businesses (e.g. Baden et al., 2009; Jenkins, 2006; Spence, 2007). In addition, some research has shown that an SME owner-manager's sense of moral duty does not always result in associated 
environmental improvement action (e.g. Hitchens et al., 2005; McKeiver \& Gadenne, 2005; Redmond et al., 2008; Revell et al., 2009; Tilley, 1999). This suggests that moral duty is not always sufficient to encourage environmental improvement reporting or communication by SME owner-managers.

Another critical factor influencing environmental improvement by SMEs is whether there is a compelling business case, which can either take the form of cost reductions and/or customer demand (Drake et al., 2004; Revell \& Blackburn, 2007). For example, some authors have found that environmental improvement can help SMEs to improve their reputation with and support by customers (Altham, 2007; Collins et al., 2007; Graafland \& Smid, 2004; Granek \& Hassanali, 2006), and thus encourage SMEs to communicate their activities. Others have found that some SMEs are required by their large customers to engage in and report on environmental improvement as a precondition to become a supplier (Baden et al., 2009; Pedersen, 2009). Where there is insufficient customer demand for environmental improvement, however, SME owner-managers will not perceive any business case for engaging in or communicating such activities to stakeholders (Gadenne et al., 2008; Lawrence et al., 2006; Mir, 2008; Simpson et al., 2004). In addition, research has also shown that owner-managers often perceive environmental improvement as a cost rather than an opportunity to reduce operational costs (Parker et al., 2009; Revell \& Blackburn, 2007; Simpson et al., 2004; Studer et al., 2006)

While the literature suggests that not all SMEs will engage in environmental improvement, it does emphasise that some SMEs will do so and elect to communicate or report their activities to stakeholders.

\section{Environmental Improvement Activity Communication by SMEs}

The limited research concerning the communication practices of SMEs suggests that they tend not to prepare or communicate their environmental improvement activities using reports (Lawrence et al., 2006; Nielsen \& Thomsen, 2009). Instead, communication often takes the form of displaying awards and accreditations (Altham, 2007; Jenkins, 2006; Murillo \& Lozano, 2006) or in other instances promoting their environmental activities on their websites (Jenkins, 2006; Murillo \& Lozano, 2006; Nielsen \& Thomsen, 2009; Zackrisson et al., 2008). There are also third-party websites which SMEs can use to report on their environmental improvement activities such as www.csr-supplychain.org and www.goodbusinessregister.com.au. The existing research has mainly reported on what channels SMEs use to communicate their environmental improvement activities, but not how they use these channels.

Accordingly the focus of this study was to identify how Australian SMEs use the specific marketing channel of websites, if at all, to communicate their environmental improvement activities. Websites were chosen as the medium for this study because past IS/eBusiness research has found that a key role for website use by SMEs relates to stakeholder communication such as promoting the company and its products/services and offering online customer support (Alam, 2009; Saban \& Rau, 2005; Sophonthummapharn, 2009; Tan et al., 2009). Websites also have the advantage that they can contain large amounts of information, compared to other media such as printed brochures, so that it was more likely that SMEs with websites might at least mention their environmental improvement activities via this channel if they want to communicate them at all.

A further rationale for this study was that (with the increasing focus on climate change issues in the Australian and global media) we believed it was an opportune time to determine if environmental improvement activities were being communicated online. This study will therefore serve as a "snapshot" of the current state of online communication of environmental improvement activities by Australian SMEs which can be used for longitudinal comparison purposes. 


\section{RESEARCH APPROACH}

The Yahoo Small Business Directory (2009) database was used to collect data for this study. We chose this database because it had a comprehensive listing of Australian businesses including website addresses, it was free and public, and large businesses were less likely to add themselves because the database was prominently labelled as "small business". We mitigated the risk that non-Australian or large businesses were included by studying websites with ".au" in their domain, and excluding them if their website indicated they were a (subsidiary of a) large or overseas firm.

Next, we selected a subset of the industry sectors based on two criteria: it had the largest number of organisations (to increase the chances of finding SMEs with websites and those communicating environmental improvement activities); and it was mentioned in the literature referring to SMEs and environmental improvement. The sectors which satisfied both criteria were manufacturing, construction (Bradford \& Fraser, 2008; Drake et al., 2004; Revell \& Blackburn, 2007; Roy \& Therin, 2008; Williamson et al., 2006) and information media and telecommunications (this sector includes printing SMEs which have been studied by Masurel, 2007; Patton \& Worthington, 2003; Rothenberg $\&$ Becker, 2004; Worthington \& Patton, 2005). These sectors are the focus of much existing research in an SME context where it is argued that these firms have the potential for major negative impacts on the environment. We also included the Electricity, Gas, Water and Waste Services sector because we anticipated that these SMEs were likely to promote services with an environmental improvement dimension. Table 1 illustrates that we found 443 accessible Australian SME websites which satisfied our selection criteria.

\begin{tabular}{|l|r|r|r|r|r|}
\hline \multicolumn{1}{|c|}{ Sector } & Total & Website & $\begin{array}{c}\text {.au } \\
\text { domain }\end{array}$ & $\begin{array}{c}\text { Active } \\
\text { website }\end{array}$ & $\begin{array}{c}\text { Environmental } \\
\text { Improvement }\end{array}$ \\
\hline Construction & 492 & 138 & 120 & 104 & $12(11.5 \%)$ \\
\hline Manufacturing & 338 & 203 & 157 & 139 & $23(16.5 \%)$ \\
\hline $\begin{array}{l}\text { Information media \& } \\
\text { telecommunications }\end{array}$ & 333 & 271 & 216 & 188 & $4(2 \%)$ \\
\hline Electricity, water, gas, waste services & 57 & 18 & 13 & 12 & $8(67 \%)$ \\
\hline Total & $\mathbf{1 , 2 2 0}$ & $\mathbf{6 3 0}$ & $\mathbf{5 0 6}$ & $\mathbf{4 4 3}$ & $\mathbf{4 7 ( 1 1 \% )}$ \\
\hline
\end{tabular}

Table 1: Australian SME Websites Communicating Environmental Improvement Activities

We next analysed each website for statements, paragraphs and in some cases entire web pages relating to environmental improvement, including any statements concerning water, waste, energy, emissions and pollution. Out of 443 websites reviewed, 47 of them were found to be communicating environmental improvement activities (see Table 1) at least to some extent.

All website information which included communication of environmental improvement activity was copied into a word processing document and used as the basis for an analysis of the emerging themes relating to how these activities were communicated. It was impractical, given the number of websites, for each website to be analysed by two researchers independently. We mitigated researcher bias and inconsistency, however, by copying any text which we thought might be relevant and then each researcher analysed the text for themes independently. We will use our findings from this exploratory research as the basis for developing a more systematic, structured approach to analysing the websites in future research which will address these limitations. In addition, in future research we will randomly select websites for independent verification checks.

The findings are presented in the next section. 


\section{RESEARCH FINDINGS}

\section{Overview of Environmental Improvement Communication by SMEs}

We found that $11 \%$ of the accessible Australian SME websites communicated environmental improvement activities (see Table 1). There is indicative evidence of a sectoral effect when noting that the Information Media \& Telecommunications sector tended to be less explicit compared to the other sectors when it came to communicating environmental improvement activities (that is, only $2 \%$ compared with $11 \%$ of higher for the other three sectors). Future research is required to explore further whether there are sectoral differences in the prevalence of online environmental improvement communication by Australian SMEs.

It is important to emphasise, however, that this does not mean that those SMEs which have not communicated environmental improvement activities on their website are not engaging in these activities. Instead, it raises the question of what rationale SME owner-managers use (assuming they are undertaking environmental improvement activities) to decide whether to communicate their activities via their website and how much detail they should provide.

It is perhaps not surprising that most of the SMEs offering electricity, gas, waste or water services (who had a website) did communicate their services as examples of environmental improvement. For example, most of the electricity service businesses described and sold solar energy products and services, and therefore there was an opportunity for them to communicate their environmental improvement activities online. As one SME stated on its home page:

"WHAT WE DO. We are a ONE-STOP SHOP to design, supply and install a wide range of technologies to save water and energy. We also carry out water and energy audits and automatic PC based monitoring systems to your requirements". [The original website text included capital letters.]

The SMEs providing water supply, sewerage and drainage services mainly provided water tank solutions for water conservation.

The remainder of this section presents our analysis of the results categorised under the major themes which emerged in terms of how the SMEs communicated their environmental improvement activities via their websites.

\section{Communicating an Environmental Improvement Profile}

The content analysis method used in this study did not allow us to determine the rationale behind the SME owner-managers' online communication approaches. However, our interpretation of the content on the websites provided indicative evidence of how some owner-managers appeared to be communicating an environmental improvement profile for their company. In some of the websites this took the form of statements about environmental commitment, missions, industry leadership, and awards and accreditations.

There were a number of the SME websites which made generic statements about the company's commitment to environmental improvement. We found a number of statements similar to this one:

"We have a wealth of knowledge and enthusiasm for environmentally conscience building ... through ecologically sound practices ...."

Another company mentioned:

"We believe in being an industry leader and informing clients about the impact their decisions may have on the environment." 
Some websites incorporated environmental improvement activities into the company's mission statements or visions, such as this one from a wood product manufacturer:

"Our wood is recovered from urban trees (street, garden \& park trees) that have been destined for removal usually for safety reasons, or due to old age or ill health. Where the wood waste would otherwise be destined for urban landfill, it is diverted from the waste stream and converted into a useful resource by our business, thereby reducing waste into our municipal tips. Also, by salvaging useable timber out of our urban forests, it helps to alleviate some of the pressure placed on our native forest resources."

Other websites included statements about awards such as in the following example:

"... was the proud recipient of the Newcastle MBA Judges Award' for Energy Efficiency in the 2002 Excellence in Building Award."

An alternative way in which some SME websites appeared to communicate a commitment to environmental improvement was by demonstrating their close ties with local/state governments or communicating a hands-on involvement with the community:

"We are certified trainers and hold a Certificate IV in training and assessment for small groups. We have experience in travelling to remote communities and training people in the art of mudearth brick making. The result is a more self-sustainable, skilled workforce, which can lead to employment opportunities, cost savings and strong community involvement."

The above-mentioned examples suggest that some SME websites are communicating an environmental improvement profile or image for the company by describing their environmental commitment, experience and knowledge, leadership and achievements.

\section{Communicating Environmental Improvement Features of Products/services}

A strong theme which emerged from the content analysis was that many SME websites described the environmental improvement features of their products/services. As expected, the nature and extent of this type of communication depended on the industry (sub-)sectors.

We anticipated that within the building industry there would be considerable communication by the SMEs about how their products/services contribute toward energy efficiency, especially given the growing concern over climate change. Surprisingly this was not the case. Only a few of the building related SMEs promoted the energy efficiency features of their products or services. For example:

"A home by [company name] is always comfortable, healthy, innovative and sustainable.

This is achieved through the integration of high quality green materials, energy efficient construction practices and renewable energy technologies."

Similarly, within construction services all the websites analysed only hinted at some environmental benefits of their products and services. One organisation, for instance, offered insulation but chose not to describe any of the environmental benefits. For SMEs which did emphasise the environmental improvement features of their products or services, there were only short references as evident in the following examples from two companies:

"... installation of rainwater tanks and water pumps ..."

"... sales and installation of premium quality water tanks for storage of rainwater, Water for livestock ...."

Future research is needed to investigate the rationale for why the majority of the building and construction SMEs in our sample were not taking (for instance) marketing advantage of the environmental improvement activities in relation to the built environment following increased awareness by the community of greenhouse gas emission and climate change issues. 
SMEs in food related sectors focused on natural/organic ingredients such as "... using no artificial colours or flavours..." or emphasised that:

"... you receive pure, natural products with no nasty chemicals ... or organic products are grown, processed and handled without the use of synthetic chemicals, artificial fertilisers, food irradiation or genetically modified ingredients."

Organic products are relevant in an environmental improvement context because the emphasis is on ensuring that the environment is used in a sustainable manner and is not contaminated with pesticides/chemicals. This emphasise on organic produce by SME food manufacturers is perhaps not surprising because understanding and appreciation by the Australian community of such issues has existed for a longer period of time when compared to more recent climate change concerns.

Another sector that emphasised the environmental improvement features of their products was the Clothing, Leather, Textiles and Footwear sub-sector of the manufacturing sector. In this sub-sector the focus was on the re-usability and wash-ability of products and the resulting reduction in waste this causes.

It therefore appears that some SME owner-managers have recognised the benefits of their products/services in reducing environmental impacts and have communicated these benefits online.

\section{Communicating Environmental Improvement Features of Business Processes}

Another strong theme which emerged was that some SME websites described the environmental improvement features of their business processes. The adoption of environmentally responsible business processes provides SMEs with an opportunity to increase efficiencies and reduce operational costs, while at the same time helping the environment. However, only a small number of SMEs described the environmental improvement features of their business processes and in these instances it was related to their core business. One example came from a painting and decorating company:

"... the ... wash system is used to minimise water usage and waste disposal ... converts water based paint into clear water and solid waste, allowing for easier and safer disposal ... the clean water can be disposed to into your garden."

Very few of the sample SME websites communicated their environmentally responsible business processes as a potential strength. One website described a new business process for car painting (which they stated was the first of its kind):

"... a purpose designed \& built full size Booth is now in place with great lighting \& dust extraction equipment, which is unique in it self as no air is emitted out side. It is fully selfcontained with the air going through a cyclone \& then special filters and recycled back, so we are also doing our bit for the environment."

The sectors where environmentally responsible business processes appeared to be the most prominent was printing and publishing SMEs within the Information Media and Telecommunications sector. One SME stated that their:

"... inks contain no volatile organic compounds (VOCs) and require no special ventilation. This is beneficial to both the environment and the people using this product ... we offset the greenhouse gas pollution produced by our business including our vehicles."

Another notable example from this sector was an SME which was fully focused on its impact on the environment and therefore pledged:

"... for every online business card order, we will plant one Australian native tree to offset carbon emissions ... uses $100 \%$ accredited natural energy ... totally environmentally friendly business cards made with totally recycled paper stocks, environmentally safe chemicals, and green power." 
It therefore appears that some SME owner-managers have not only recognised the environmental impact of their business processes, but have also communicated their efforts to reduce this impact via their websites.

\section{Prominence of Environmental Improvement Communication}

The final theme which appeared quite strongly in our analysis related to design of the SMEs' websites in terms of the prominence of the environmental improvement communication. For example, some websites included clear and prominent statements, typically about their environmental improvement activities, on their home pages. This was especially the case for those SMEs which were communicating an environmental improvement profile as discussed earlier. For other websites this prominence took the form of a dedicated menu heading relating to environmental improvement, which had the same prominence as main menu (or navigation) options such as their product/service, "about us" and "contact us" pages. In these instances the communication was quite obvious as soon as we visited the home page of the website.

For other websites their environmental improvement communication was not immediately obvious and more difficult to find. For instance, some websites communicated their activities on their "About us" page or, in one case, on a page called "News". In these instances the environmental improvement activities of the SME would not be clear to a website visitor unless they happen to click on and read these pages or were actively searching for environment improvement information. In some cases these pages were the only places on the website where environmental improvement activities were communicated, so there was a potential risk that visitors may miss this information unless once again they were specifically looking for it.

\section{DISCUSSION AND FUTURE RESEARCH DIRECTIONS}

It has been argued by some authors (e.g. Zontanos \& Anderson, 2004) that the traditional 4 Ps (product, promotion, price and place) which are the conceptual underpinning of marketing may not be applicable to SMEs. Based on our findings we recommend another way of conceptualising online communication by SMEs of their environmental improvement activities by using an alternative set of 4 Ps: profile; product; process and prominence. These 4 Ps can form the foundation pillars for developing practical guidelines to help SME owner-managers to communicate their environmental improvement activities more effectively. We now discuss each of these Ps in relation to the literature and suggest avenues for future research which have arisen from our analyses.

The findings suggest that SME owner-managers can use their website to communicate an environmental improvement profile (the first "P") for the company by describing their environmental commitment, mission, vision, experience and knowledge, leadership, awards and achievements. The use of environmental improvement for these purposes is consistent with the environmental literature which suggests that SMEs can use these activities for marketing advantage (Jenkins, 2006; Lawrence et al., 2006; Murillo \& Lozano, 2006; Nielsen \& Thomsen, 2009; Zackrisson et al., 2008). It is also consistent with the IS/eBusiness literature which suggests that SMEs can use websites to present information about the identity and image of the company (Alonso-Mendo et al., 2009; Alonso Mendo \& Fitzgerald, 2005; Burgess \& Bingley, 2007). Future research is needed, however, to interview or survey SME owner-managers of these websites to determine whether these forms of environmental improvement communication has resulted in any competitive advantage for their business or more generally in their industry, and whether such communication means customers are more likely to conduct business with them. 
The second "P" highlights another form of environmental improvement communication which relates to the products offered by the company. The results suggest there were some grassroots beginnings in areas where consumers appear to demanding environmentally responsible products/services such as organic food or sustainable buildings. This is consistent with research in IS/eBusiness which suggests that SMEs can use websites to promote their products/services online (Alonso-Mendo et al., 2009; Alonso Mendo \& Fitzgerald, 2005; Burgess \& Bingley, 2007). However, our findings also raise the question of why many SMEs who appear to offer products/services with environmental improvement features do not communicate these qualities on their websites. Is it because, as suggested in the literature, that owner-managers do not perceive a benefit in communicating these features (Gadenne et al., 2008; Lawrence et al., 2006; Mir, 2008; Simpson et al., 2004)? Do they believe that such communication might instead put them at a competitive disadvantage because they perceive their customers are not looking for such features? Alternatively, will longitudinal research show that such communication practices might increase over time as transparency and initiatives (such as a carbon trading scheme and other regulations) relating to environmental improvement become more common in the marketplace? The most surprising aspect of our findings was that not a single SME in the information media and telecommunications sector had promoted their products or services as environmentally responsible. For example, there is the potential of telecommuting and teleconferencing to reduce the need for travel and associated carbon emissions. There was also no mention on the websites of these SMEs about offering carbon neutral IT/IS services. The reasons behind this lack of (communication about such) activity warrants further investigation.

The next "P" which emerged from the results related to describing the environmental improvement features of an SME's business processes. While the potential for SMEs to develop environmentally responsible processes is acknowledged in the environment literature (Aragon-Correa et al., 2008; Bos-Brouwers, 2009; Collins et al., 2007; Rao et al., 2009; Revell et al., 2009), the IS/eBusiness literature does not tend to mention that SME websites can be used to describe business processes (e.g. see Alonso-Mendo et al., 2009; Alonso Mendo \& Fitzgerald, 2005; Burgess \& Bingley, 2007). Indeed, we found that descriptions of environmentally responsible business processes were not common among the SME websites studied, which raises some potential questions for future research. For example, are most SMEs not aware of environmentally responsible business processes? Are the processes adopted by SMEs not environmentally responsible or do SMEs not wish to communicate the environmental improvements they have made to their processes (and if so why)? Are customers of certain industries more sensitive to environmentally responsible processes than those in other industries? Or is it too complicated and resource intensive for SMEs to describe the environmental improvement features of their business processes to their customers?

Prominence is the final "P" as is related to how the SME websites communicated environmental improvement activities. We found considerable variation among websites into terms of how easy or difficult it was to locate environmental improvement related content. For example, some websites included this content prominently on home pages, slightly less prominently with devoted pages linked to via a main menu, or embedded more subtly in other pages which required more effort to locate. In some cases the websites had quite extensive communication about environmental improvement, while for others there were just one or two sentence statements. These results extend the existing IS/eBusiness research on SME website design issues which has largely focused on, for instance, website usability, accessibility and attractiveness (Alonso-Mendo et al., 2009; Alonso Mendo \& Fitzgerald, 2005; Fisher et al., 2007; Harris \& Rae, 2009; Lazarinis et al., 2008; Thrassou \& Vrontis, 2008) rather than the more functional aspects of design. These findings also raise questions for future research. For example, what was the rationale of SME owner-managers (or website designers if these were not the same people) for deciding how prominent the environmental improvement communication should be on their website? To what extent do owner-managers believe their customers are looking for or assessing environmental improvement activities when selecting an 
organisation? What are the issues which do (or should) be considered when designing a website with respect to environmental improvement communication?

It is clear from this study that there are many varied approaches used by SME owner-managers and their websites to communicate their environmental improvement activities.

\section{CONCLUSIONS}

This paper fills a gap in the literature and knowledge with respect to how SMEs promote their environmental improvement activities to stakeholders by examining how Australian SMEs are using (and designing) their websites to communicate their environmental improvement activities. The existing literature suggests that many SMEs might feel uncomfortable about communicating their environmental improvement activities for various reasons (eg, Baden et al., 2009; Jenkins, 2006; Spence, 2007). However, our research provides insights into how those who do communicate their environmental improvement activities achieve this via their websites.

Our findings show that there is considerable variation in how the websites are used. For example, the study showed that some SMEs use their website to promote an environmental improvement profile, while others describe the environmental improvement features of their products/services. Some have used the website to communicate the ways in which they have changed their business processes to be more environmentally responsible. Some provide extensive information, while others opt more for brief one or two sentence statements. Some SME owner-managers have designed their website so that their environmental improvement activities or commitment is communicated very prominently such as on home pages and devoted web pages, while for others a visitor must explicitly search for communication about an SME's environmental improvement.

While these insights are useful and interesting, we must emphasise that this is the first stage of a larger research project which will investigate (among other things) the why questions posed during our discussion of the findings. It will therefore be important to complement these observational findings (which are purely our interpretations of the website content) with questionnaire surveys and interviews of the SME owner-managers of these businesses. This will help us to gain an understanding of the issues underpinning the choices of whether or not to communicate their environmental improvement activities and the decisions regarding website design. This work will result in more in-depth insights into the roles played by different channels of communication which, in addition to websites, can include formal reports, face-to-face communication with stakeholders, brochures and third-party reporting services. We will also undertake similar content analyses of the SME websites in other industry sectors to develop a more complete picture of environmental improvement communication approaches used across the broad SME sector. This is significant because the promotional practices and rationale may vary between sectors and these differences will need to be acknowledged and incorporated as part of future environmental improvement policies relating to and funding to support SMEs. In addition, we would like to undertake a study of SME websites globally to determine whether there are differences in environmental improvement communication when comparing SMEs from different countries. Such a cross-country comparison might determine, for instance, how Australian SMEs compare with other countries in terms of the sophistication and nature of their communication about environmental improvement activities. 


\section{REFERENCES}

ABS (2007) Counts of Australian businesses, including entries and exits, Catalogue No. 8165.0, Australian Bureau of Statistics, Canberra.

Alam, S.S. (2009) "Adoption of internet in Malaysian SMEs", Journal of Small Business and Enterprise Development, Vol 16 No 2, pp 240-255.

Alonso-Mendo, F., Fitzgerald, G. \& Frias-Martinez, E. (2009) "Understanding web site redesigns in small- and medium-sized enterprises (SMEs): a U.K.-based study on the applicability of ecommerce Stage Models", European Journal of Information Systems, Vol 18 No 3, pp 264279.

Alonso Mendo, F. \& Fitzgerald, G. (2005) "A multidimensional framework for SME e-business progression", Journal of Enterprise Information Management, Vol 18 No 6, pp 678-696.

Altham, W. (2007) "Benchmarking to trigger cleaner production in small business: drycleaning case study", Journal of Cleaner Production, Vol 15 No 8-9, pp 798-813.

Aragon-Correa, J.A., Hurtado-Torres, N., Sharma, S. \& Garcia-Morales, V.J. (2008) "Environmental strategy and performance in small firms: a resource-based perspective", Journal of Environmental Management, Vol 86 No 1, pp 88-103.

Australian Government (2010) "Know your obligations", Department of Climate Change. http://www.climatechange.gov.au/en/business/obligations.aspx (accessed 3 March 2010).

Baden, D.A., Harwood, I.A. \& Woodward, D.G. (2009) "The effect of buyer pressure on suppliers in SMEs to demonstrate CSR practices: an added incentive or counter productive?", European Management Journal, Vol 27 No 6, pp 429-441.

Blomback, A. \& Wigren, C. (2009) "Challenging the importance of size as determinant for CSR activities", Management of Environmental Quality: An International Journal, Vol 20 No 3, pp 255-270.

Bos-Brouwers, H.E.J. (2009) "Corporate sustainability and innovation in SMEs: evidence of themes and activities in practice", Business Strategy and the Environment, Vol in press.

Bradford, J. \& Fraser, E.D.G. (2008) "Local authorities, climate change and small and medium enterprises: identifying effective policy instruments to reduce energy use and carbon emissions", Corporate Social Responsibility and Environment Management, Vol 15 No 3, pp 156-172.

Burgess, S. \& Bingley, S. (2007) "One size does not fit all: website content of Australian community based organisations", 11th Pacific-Asia Conference on Information Systems, 3-6 July, Auckland, New Zealand.

Capra, E. \& Merlo, F. (2009) "Green IT: everything starts from the software", 17th European Conference on Information Systems, 8-10 June, Verona, Italy, pp 62-73.

Clement, K. \& Hansen, M. (2003) "Financial incentives to improve environmental performance: a review of Nordic public sector support for SMEs", European Environment, Vol 13 No 1, pp 34-47.

Collins, E., Lawrence, S., Pavlovich, K. \& Ryan, C. (2007) "Business networks and the uptake of sustainability practices: the case of New Zealand", Journal of Cleaner Production, Vol 15 No 8-9, pp 729-740.

Condon, L. (2004) "Sustainability and small to medium sized enterprises : how to engage them", Australian Journal of Environmental Education, Vol 20 No 1, pp 57-67. 
Drake, F., Purvis, M. \& Hunt, J. (2004) "Meeting the environmental challenge: a case of win-win or lose-win? A study of the UK baking and refrigeration industries", Business Strategy and the Environment, Vol 13 No 3, pp 172-186.

Elliott, S. (2007) "Environmentally sustainable ICT: a critical topic for IS research?", 11th PacificAsia Conference on Information Systems, 3-6 July, Auckland, New Zealand.

Elliott, S. (2009) "Developing organizational capabilities in SMEs: enabling environmentally sustainable ICT", 22nd Bled eConference, 14-17 June, Bled, Slovenia.

Environmental Agency (2002) "How green are small businesses? A snapshot of environmental awareness and practice in small and medium enterprises (SMEs)", Environment Agency, NetRegs, UK. http://www.netregs.gov.uk/netregs/links/98674.aspx (accessed 20 January 2008).

Fisher, J., Craig, A. \& Bentley, J. (2007) "Moving from a web presence to e-commerce: the importance of a business - web strategy for small-business owners", Electronic Markets, Vol 17 No 4, pp 253-262.

Gadenne, D.L., Kennedy, J. \& McKeiver, C. (2008) "An empirical study of environmental awareness and practices in SMEs", Journal of Business Ethics, Vol 84 No 1, pp 45-63.

Graafland, J.J. \& Smid, H. (2004) "Reputation, corporate social responsibility and market regulation", Tijdschrift voor Economie en Management, Vol XLIX No 2, pp 271-308.

Granek, F. \& Hassanali, M. (2006) "The Toronto Region Sustainability Program: insights on the adoption of pollution prevention practices by small to medium-sized manufacturers in the Greater Toronto Area (GTA)", Journal of Cleaner Production, Vol 14 No 6-7, pp 572-579.

Gueben, C. \& Skerratt, R.G. (2007) "SMEs and environmental communications: motivations and barriers to environmental reporting", International Journal of Environment and Sustainable Development, Vol 6 No 1, pp 1-16.

Gunningham, N. \& Sinclair, D. (2002) "Partnerships, management systems and the search for innovative regulation in the vehicle body shop industry", Business Strategy and the Environment, Vol 11 No 4, pp 236-253.

Haddock-Fraser, J. \& Fraser, I. (2008) "Assessing corporate environmental reporting motivations: differences between 'close-to-market' and 'business-to-business' companies", Corporate Social Responsibility and Environment Management, Vol 15 No 3, pp 140-155.

Harris, L. \& Rae, A. (2009) "The revenge of the gifted amateur ... be afraid, be very afraid ...", Journal of Small Business and Enterprise Development, Vol 16 No 4, pp 694-709.

Hitchens, D., Thankappan, S., Trainor, M., Clausen, J. \& De Marchi, B. (2005) "Environmental performance, competitiveness and management of small businesses in Europe", Tijdschrift voor Economische en Sociale Geografie, Vol 96 No 5, pp 541-557.

Howgrave-Graham, A. \& van Berkel, R. (2007) "Assessment of cleaner production uptake: method development and trial with small businesses in Western Australia", Journal of Cleaner Production, Vol 15 No 8-9, pp 787-797.

Jenkins, H. (2006) "Small business champions for corporate social responsibility", Journal of Business Ethics, Vol 67 No 3, pp 241-256.

Kerr, I.R. (2006) "Leadership strategies for sustainable SME operation", Business Strategy and the Environment, Vol 15 No 1, pp 30-39.

Lawrence, S., Collins, E., Pavlovich, K. \& Arunachalam, M. (2006) "Sustainability practices of SMEs: the case of NZ", Business Strategy and the Environment, Vol 15 No 4, pp 242-257. 
Lazarinis, F., Kanellopoulos, D. \& Lalos, P. (2008) "Heuristically evaluating Greek e-tourism and emuseum websites", Electronic Journal of Information Systems Evaluation, Vol 11 No 1, pp 1726.

Maali, B., Casson, P. \& Napier, C. (2006) "Social reporting by Islamic banks", Abacus, Vol 42 No 2.

MacGregor, R.C. \& Vrazalic, L. (2005) "A basic model of electronic commerce adoption barriers: a study of regional small businesses in Sweden and Australia", Journal of Small Business and Enterprise Development, Vol 12 No 4, pp 510-527.

Marshall Report (1998) Economic instruments and the business use of energy, Task Force Report, Stationery Office, London.

Martin, A.D. \& Hadley, D.J. (2008) "Corporate environmental non-reporting - a UK FTSE 350 perspective", Business Strategy and the Environment, Vol 17 No 4, pp 245-259.

Masurel, E. (2007) "Why SMEs invest in environmental measures: sustainability evidence from small and medium-sized printing firms", Business Strategy and the Environment, Vol 16 No 3, pp 190-201.

McKeiver, C. \& Gadenne, D. (2005) "Environmental management systems in small and medium businesses", International Small Business Journal, Vol 23 No 5, pp 513-537.

Mir, D.F. (2008) "Environmental behaviour in Chicago automotive repair micro-enterprises (MEPs)", Business Strategy and the Environment, Vol 17 No 3, pp 194-207.

Molla, A. (2009) "Organizational motivations for green IT: exploring green IT matrix and motivation models", 13th Pacific-Asia Conference on Information Systems, 10-12 July, Hyderabad, India.

Murillo, D. \& Lozano, J.M. (2006) "SMEs and CSR: an approach to CSR in their own words", Journal of Business Ethics, Vol 67 No 3, pp 227-240.

Nielsen, A.E. \& Thomsen, C. (2009) "CSR communication in small and medium-sized enterprises: a study of the attitudes and beliefs of middle managers", Corporate Communications: An International Journal, Vol 14 No 2, pp 176-189.

Parker, C.M., Redmond, J. \& Simpson, M. (2009) "A review of interventions to encourage SMEs to make environmental improvements", Environment and Planning C: Government and Policy, Vol 27 No 2, pp 279-301.

Patton, D. \& Worthington, I. (2003) "SMEs and environmental regulations: a study of the UK screenprinting sector", Environment and Planning C: Government and Policy, Vol 21 No 4, pp 549566.

Pedersen, E.R. (2009) "The many and the few: rounding up the SMEs that manage CSR in the supply chain", Supply Chain Management: An International Journal, Vol 14 No 2, pp 109-116.

Pimenova, P. \& van der Vorst, R. (2004) "The role of support programmes and policies in improving SMEs environmental performance in developed and transition economies", Journal of Cleaner Production, Vol 12 No 6, pp 549-559.

Piotrowicz, W. \& Cuthbertson, R. (2009) "Sustainability - a new dimension in information systems evaluation", Journal of Enterprise Information Management, Vol 22 No 5, pp 492-503.

Pollach, I., Scharl, A. \& Weichselbraun, A. (2009) "Web content mining for comparing corporate and third-party online reporting: a case study on solid waste management", Business Strategy and the Environment, Vol 18 No 3, pp 137-148.

Rao, P., Singh, A.K., la O'Castillo, O., Intal, P.S., Jr. \& Sajid, A. (2009) "A metric for corporate environmental indicators ... for small and medium enterprises in the Philippines", Business Strategy and the Environment, Vol 18 No 1, pp 14-31. 
Redmond, J., Walker, E.A. \& Wang, C. (2008) "Issues for small businesses with waste management", Journal of Environmental Management, Vol 88 No 2, pp 275-285.

Revell, A. \& Blackburn, R.A. (2007) "The business case for sustainability? An examination of small firms in the UK's construction and restaurant sectors", Business Strategy and the Environment, Vol 16 No 6, pp 404-420.

Revell, A., Stokes, D. \& Chen, H. (2009) "Small businesses and the environment: turning over a new leaf?", Business Strategy and the Environment, Vol in press.

Rothenberg, S. \& Becker, M. (2004) "Technical assistance programs and the diffusion of environmental technologies in the printing industry: the case of SMEs", Business \& Society, Vol 43 No 4, pp 366-397.

Roy, M.-J. \& Therin, F. (2008) "Knowledge acquisition and environmental commitment in SMEs", Corporate Social Responsibility and Environment Management, Vol 15 No 5, pp 249-259.

Saban, K. \& Rau, S. (2005) "The functionality of websites as export marketing channels for small and medium enterprises", Electronic Markets, Vol 15 No 2, pp 128-135.

Schaper, M. (2002) "Small firms and environmental management: predictors of green purchasing in Western Australian pharmacies", International Small Business Journal, Vol 20 No 3, pp 235251.

Sensis (2009) "Sensis e-Business Report: the online experience of small and medium enterprises", Sensis. http://about.sensis.com.au/IgnitionSuite/uploads/docs/2009_Sensis_eBusiness_Report.pdf (accessed 9 February 2010).

Simpson, M., Taylor, N. \& Barker, K. (2004) "Environmental responsibility in SMEs: does it deliver competitive advantage?", Business Strategy and the Environment, Vol 13 No 3, pp 156-171.

Sophonthummapharn, K. (2009) "The adoption of techno-relationship innovations: a framework for electronic customer relationship management", Marketing Intelligence \& Planning, Vol 27 No 3, pp 380-412.

Spence, C. (2009) "Social and environmental reporting and the corporate ego", Business Strategy and the Environment, Vol 18 No 4, pp 254-265.

Spence, L.J. (2007) "CSR and small business in a European policy context: the five "C"s of CSR and small business research agenda 2007", Business and Society Review, Vol 112 No 4, pp 533552.

Studer, S., Welford, R. \& Hills, P. (2006) "Engaging Hong Kong businesses in environmental change: drivers and barriers", Business Strategy and the Environment, Vol 15 No 6, pp 416-431.

Tan, K.S., Chong, S.C., Lin, B. \& Eze, U.C. (2009) "Internet-based ICT adoption: evidence from Malaysian SMEs", Industrial Management \& Data Systems, Vol 109 No 2, pp 224-244.

Tate, W.L., Ellram, L.M. \& Kirchoff, J.F. (2009) "Corporate social responsibility reports: a thematic analysis related to supply chain management", Journal of Supply Chain Management, Vol 46 No 1, pp 19-44.

Thrassou, A. \& Vrontis, D. (2008) "Internet marketing by SMEs: towards enhanced competitiveness and internationalisation of professional services", International Journal of Internet Marketing and Advertising, Vol 4 No 2/3, pp 241-261.

Tilley, F. (1999) "The gap between the environmental attitudes and the environmental behaviour of small firms", Business Strategy and the Environment, Vol 8 No 4, pp 238-248.

Vykoukal, J., Wolf, M. \& Beck, R. (2009) "Does green IT matter? Analysis of the relationship between green IT and grid technology from a resource-based view perspective", 13th PacificAsia Conference on Information Systems, 10-12 July, Hyderabad, India. 
Walker, E.A., Redmond, J. \& Wang, C. (2008) "Waste recycling: local methods for successful interaction with small business", International Journal of Environment and Sustainable Development, Vol 7 No 4, pp 363-382.

Williamson, D., Lynch-Wood, G. \& Ramsay, J. (2006) "Drivers of environmental behaviour in manufacturing SMEs and the implications for CSR", Journal of Business Ethics, Vol 67 No 3, pp 317-330.

Worthington, I. \& Patton, D. (2005) "Strategic intent in the management of the green environment within SMEs: an analysis of the UK screen-printing sector", Long Range Planning, Vol 38 No 2, pp 197-212.

Yahoo Small Business Directory (2009) "Small business information from Kochie's business builders". http://smallbusiness.yahoo.com.au/SmallBusinessDirectory/SearchResults.aspx (accessed 26 June 2009).

Zackrisson, M., Rocha, C., Christiansen, K. \& Jarnehammar, A. (2008) "Stepwise environmental product declarations: ten SME case studies", Journal of Cleaner Production, Vol 16 No 17, pp 1872-1886.

Zontanos, G. \& Anderson, A.R. (2004) "Relationships, marketing and small business: an exploration of links in theory and practice", Qualitative Market Research: An International Journal, Vol 7 No 3, pp 228-236. 